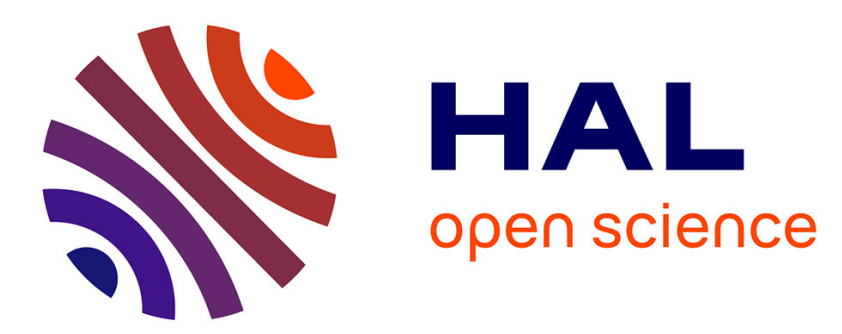

\title{
Geometrical evolution of interlocked rough slip surfaces: The role of normal stress
}

\author{
Nir Badt, Yossef H. Hatzor, Renaud Toussaint, Amir Sagy
}

\section{To cite this version:}

Nir Badt, Yossef H. Hatzor, Renaud Toussaint, Amir Sagy. Geometrical evolution of interlocked rough slip surfaces: The role of normal stress. Earth and Planetary Science Letters, 2016, 443, pp.153-161. 10.1016/j.epsl.2016.03.026 . hal-01340879

\section{HAL Id: hal-01340879 \\ https://hal.science/hal-01340879}

Submitted on 2 Jul 2016

HAL is a multi-disciplinary open access archive for the deposit and dissemination of scientific research documents, whether they are published or not. The documents may come from teaching and research institutions in France or abroad, or from public or private research centers.
L'archive ouverte pluridisciplinaire HAL, est destinée au dépôt et à la diffusion de documents scientifiques de niveau recherche, publiés ou non, émanant des établissements d'enseignement et de recherche français ou étrangers, des laboratoires publics ou privés. 
1 Geometrical evolution of interlocked rough slip surfaces: The

2 role of normal stress

3

4 Nir Badt ${ }^{1}$, Yossef H. Hatzor ${ }^{1}$, Renaud Toussaint ${ }^{2}$ and Amir Sagy ${ }^{3 *}$

5 1. Department of Geological and Environmental Science, Ben-Gurion University of the Negev, Beer Sheva 84105, Israel

2. Institut de physique du globe de Strasbourg, 5, rue René Descartes - F-67084 Strasbourg cedex

8 3. Geological Survey of Israel, 30 Malkhe Israel, Jerusalem 95501, Israel

$9 \quad *$ Corresponding author: asagy@gsi.gov.il roughness 


\section{Abstract}

We study the evolution of slip surface topography using direct shear tests of perfectly mating surfaces. The tests are performed under imposed constant normal stress and constant slip rate conditions, to a sliding distance comparable to the roughness scale of the studied surfaces.

Prismatic limestone blocks are fractured in tension using four-point bending and the generated surface topographies are measured using a laser profilometer. The initially rough fracture interfaces are tested in direct shear while ensuring a perfectly mating configuration at the beginning of each test. The predetermined sliding distance in all tests is $10 \mathrm{~mm}$ and the sliding velocity is $0.05 \mathrm{~mm} / \mathrm{s}$. A constant normal stress is maintained throughout the tests using closed loop servo control. The range of normal stresses applied is between $2 \mathrm{MPa}$ and $15 \mathrm{MPa}$. After shearing, the surface topographies are re-scanned and the geometrical evolution is analyzed. We find that surface roughness increases with increasing normal stress: under normal stresses below $5 \mathrm{MPa}$ the surfaces become smoother compared to the original geometry, whereas under normal stresses between 7.5 $\mathrm{MPa}$ and $15 \mathrm{MPa}$ the surfaces clearly become rougher following shear. Statistical spectral analyses of the roughness profiles indicate that roughness increases with length-scale. Power spectral density values parallel to the slip orientation are fitted by power-law with typical power value of 2.6, corresponding to a Hurst exponent of 0.8 , assuming self-affine roughness. This power value is consistent for the post-sheared surfaces and is obtained even when the original surface roughness does not follow initially a power-law form. The value of the scaling-law prefactor however increases with increasing normal stress. We find that the deformation associated with shearing initially rough interlocked surfaces extends beyond the immediate tested surface, further into the intact rock material. The intensity of the damage and its spatial distribution clearly increase with increasing normal stress. Wear loss is measured by subtracting the post-shear surface from the pre-shear surface matrices using known reference points. Our measurements indicate that wear loss and 
43 roughness evolution are both positively correlated with the mechanical shear work applied during

44 the experiments. We argue, therefore, that normal stress plays a significant role in the evolution of

45 interlocked surfaces, such as geological faults, and strongly affects the energy partitioning during

46 slip.

47 


\section{Introduction}

Faults in the upper crust are characterized by complex zones of deformed rock that shear during repeated faulting events (Chester \& Logan., 1986; Ben-Zion \& Sammis, 2003; Wibberley et al., 2008; Faulkner et al., 2010). Most of the displacement along faults is localized at principal slip surfaces exhibiting geometrical irregularity at all measurable scales (Power et al., 1988; Siman-Tov et al., 2013; Candela et al., 2012) and as in other material interfaces the roughness is critical to the understanding of shear and frictional processes (e.g. Bowden \& Tabor, 1950; Dieterich \& Kilgore; 1994). The presence of gouge and cataclasite zones in natural faults indicates that the fault surface itself evolves through wear production (Power et al., 1988; Wang \& Scholz, 1994). In each slip event wear is generated and the initial geometry of the slip surface is continuously modified, a process

Previous roughness evolution studies in the field by means of geometrical measurements of natural fault surfaces suggest that faults smooth with accumulated slip. Wesnousky (1988) observed strikeslip fault traces at geological map scales and discovered that the number of steps along the trace reduces with increased offset on the faults. By comparing profiles along slip surfaces that accommodated dozens to hundreds of meters of displacement to these which sheared less than a meter, Sagy et al. (2007) concluded that roughness parallel to slip orientation reduced due to slip at all measured scales. Brodsky et al. (2011) increased the sampling population and demonstrated that roughness of profiles at lengths of 0.5 to $1 \mathrm{~m}$ decreased very gradually as function of the slip amount. Bistacchi et al. (2011) studied paleo-seismic fault surfaces exhumed from seismogenic depths and demonstrated that similar geometrical evolution occurs at these depths.

Surface roughness of fractures was intensively investigated in laboratory experiments as an integral component of contact and shear mechanics (e.g. Bowden \& Tabor, 1950; Archard, 1953). Many pioneering works in rock mechanics investigated roughness of faults and fractures in relation to 
72 mechanical strength and shear resistance (Patton, 1966; Barton, 1976; Byerlee, 1978). In the last decades, quantitative statistical analysis methods to describe surface geometry were proposed (e.g. Mandelbrot, 1983; Bouchaud et al., 1990; Grasselli et al., 2002) and some were applied to describe rock discontinuities. Amitrano \& Schmittbuhl (2002) for example measured the geometry of shear

fractures formed by triaxial shear tests and suggested that they exhibited self-affine power-law geometry with Hurst exponents $H$ of 0.8 and 0.74 for profiles normal and parallel to the slip direction, respectively. Results obtained with rotary shear tests demonstrated slip rate effects on surface roughness (Fondriest et al., 2013; Boneh et al. 2014; Siman-Tov et al., 2015). These studies focused solely on the roughness characteristics after slip and therefore the actual roughness evolution through shear remained unresolved.

Roughness evolution studies require measuring the surface geometry before and after shear displacement. Renard et al. (2012) slid smooth halite surfaces on a coarse sandpaper substrate under constant normal stress and characterized the roughness exponent evolution. Davidesko et al. (2014) demonstrated that when shearing under relatively low normal stress (2 MPa) surface roughness decreased with displacement; they sheared initially rough tensile fracture surfaces produced by three-point bending to increasing slip distances, up to $15 \mathrm{~mm}$.

Normal stress is fundamental in the theory of friction and wear (Bowden \& Tabor, 1950; Archard, 1953; Byerlee, 1978) and therefore it is reasonable to assume that it also strongly affects damage and deformation in natural faults which typically yield under tectonic stresses of significant magnitudes. In the present study the effect of normal stress on roughness evolution of rock surfaces is examined by means of direct shear experiments coupled with laser profilometer measurements before and after shear. The advantage of the combined mechanical-tribological methodology adopted here is that multi-scale mating surfaces are sheared relative to each other as in natural faults, and are mapped with high precision. Moreover, the direct shear system used here 
allows great control and measuring capabilities during shear displacement. The acquired roughness data is examined both statistically, using spectral analyses, and morphologically, using crosssections and height maps of the surfaces.

99

\section{Experimental Procedure}

The experiments consist of several consequent stages: 1) rough tensile surfaces are created using four point bending; 2) both surfaces are scanned with a laser profilometer; 3) direct shear experiments under constant normal stress to target displacement of $10 \mathrm{~mm}$ are performed while ensuring the sheared surfaces are perfectly mating ; 4) re-scanning of both surfaces; 5) roughness analysis.

The experimental surfaces are generated from prismatic limestone beams. The starting material is a fine-grained limestone with an average grain diameter of $~ 0.4 \mathrm{~mm}$ known locally as "Hebron Marble". The elastic parameters of the intact rock are Young's modulus of 57 GPa and Poisson's ratio of 0.29 (Davidesko, 2013).

The four-point bending tests utilized the direct shear system with the shear load frame removed and the normal piston used to deliver the axial load (Fig. 1a). A vertical notch approximately $5 \mathrm{~cm}$ long was pre-cut to direct the propagation direction of the induced tensile fracture (see Fig. 1a). The produced surfaces were typically $8 \mathrm{~cm}$ wide and approximately $11 \mathrm{~cm}$ long. The uniqueness of the generated surfaces in this procedure is that the roughness of one surface matches exactly the roughness of the other, thus enabling the surfaces to slide relative to one another from a completely mating configuration. Furthermore, the roughness of each set (two mating surfaces) is neither predetermined nor reproducible, which better simulates natural fault surfaces. The experimental fault surfaces in the present study, therefore, differ substantially from 
the usual surfaces used in friction studies, because they allow examining of a multi-scale asperity interlocking contact (Fig. 2).

120 The experimental fault surfaces are sheared in a hydraulic, servo-controlled, direct-shear system 121 (Fig. 1c) to a constant distance of $10 \mathrm{~mm}$ at a rate of $0.05 \mathrm{~mm} / \mathrm{s}$, under imposed constant normal 122 stress so that the tested interface is allowed to dilate vertically during shear. Normal load is delivered from the axial piston which connects to the top of the shear load frame using a centering 124 pin. The lower shear box rolls on frictionless rollers that are placed between the shear box and the 125 base platen (Fig. 1d).

126 The fractured interfaces are cast in the shear boxes using cement in a completely mating 127 configuration so that when initially loaded the interlocking contacts are fully preserved. The shear 128 boxes are placed in the shear load frame which is connected to the horizontal shear piston (Fig. 1c). 129 Six linear variable displacement transducers (LVDTs) are attached to metal plates on both flanks of two horizontal transducers are used to measure shear displacement. The LVDTs monitor the displacements very close to the sliding interface, thus allowing excellent control capabilities during testing because the shear displacement feedback to the closed-loop system is obtained from the outputs of the two horizontal shear transducers.

The before and after topography of the tested interfaces is obtained by means of laser profilometer (Fig.1b) and the data are used for roughness analysis. Both top and bottom surfaces are scanned 137 before and after shear. Prior to scanning, the surfaces are cleaned of dust and moisture. Wear 138 particles are removed from the post-shear surfaces using a soft brush and air pressure. The scans 139 are performed parallel to the direction of shear (longitudinal direction of the samples) using a 75 $140 \mathrm{~mm}$ lens with a sampling frequency of $0.02 \mathrm{~mm}^{-1}$ and $34.34 \mathrm{~mm}^{-1}$ in the longitudinal and transverse 141 directions, respectively. The scans are used to map the entire surface in four parallel strips from 
which roughness analysis is performed. By comparing the results to higher resolution measurements in the same samples it is concluded that the accuracy of the measurements is robust in our samples for detecting power spectral density values for wavelengths above $0.2 \mathrm{~mm}$. All preshear scans had post-shear counterpart scans that covered the same area for later roughness comparison. The acquired scans data are presented using surface matrices of heights.

Figure 1. Experimental methods in use: (a) Prismatic limestone beam in four-point bending configuration, the length of the beam is $50 \mathrm{~cm}$ long. (b) Profilometer scanning a surface, note that the surface is fixed to a steel shear box which links the sample to the direct shear system. (c) The direct shear system: the normal piston (delineated by $n$ arrow) and the shear piston and load frame (delineated by $s$ arrow). (d) Side view of the shear load frame with the vertical and horizontal LVDTs (delineated by $\boldsymbol{v}$ and $h$ arrows, respectively).

Figure 2. Schematic illustration of tested surface configuration in typical rock friction and wear experiments (top) and the multi-scale, interlocking roughness in the present study (bottom).

\section{Mechanical Results}

The mechanical results obtained from six direct shear experiments conducted in the present study and data from one experiment conducted by Davidesko et al. (2014) are presented in Table 1 (Supplementary Material). All tests were sheared to a constant displacement of $10 \mathrm{~mm}$ at a rate of $0.05 \mathrm{~mm} / \mathrm{s}$ under constant normal stress conditions. During shear displacement, the sliding interface was allowed to dilate under the imposed normal stress; an example of a typical stress- 
Click here to download high resolution image
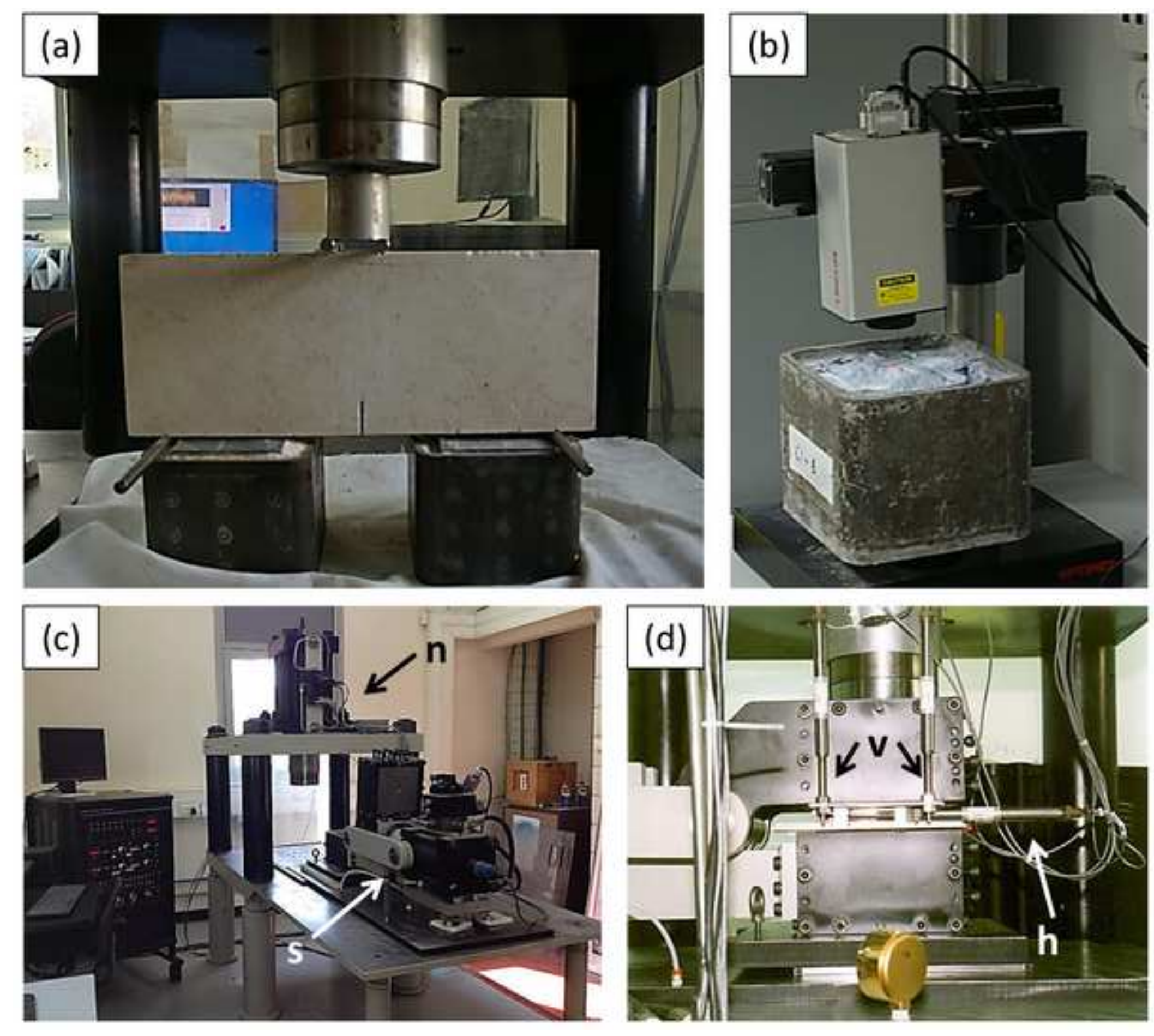


\section{Figure 2}

Click here to download high resolution image
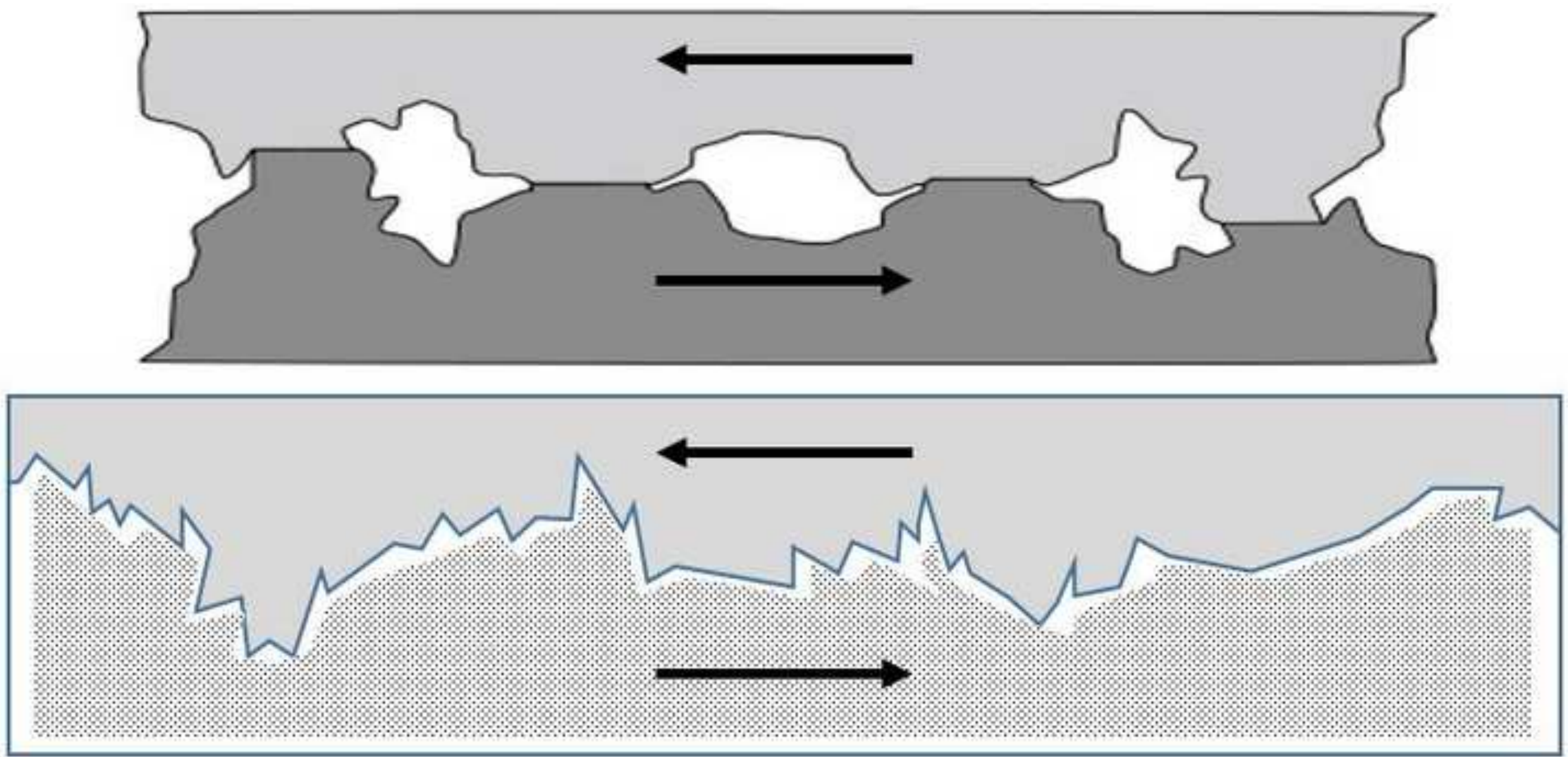
displacement curve is shown in Figure 3. The results shown in Table 1 include measured shear stress $(\tau)$ and normal stress $\left(\sigma_{n}\right)$, calculated shear resistance $\left(\tau / \sigma_{n}\right)$, and calculated stress-drop $(\Delta \tau)$ results. Shear resistance, as used here, is the value of the measured shear stress divided by the applied normal stress at any particular instance. Stress-drop refers to the change in shear stress from peak to minimum residual stress. It should be noted that while peak shear stress was clearly exhibited in all tests, a constant residual shear stress, elsewhere referred to as "steady state" (e.g. Dieterich \& Kilgore, 1994) was never reached for the pre-specified target displacement of $10 \mathrm{~mm}$. We therefore use the tail of the shear stress - shear displacement curve to assign a residual shear stress value for each test, thus obtaining the calculated stress-drop values reported in Table 1. Peak shear resistance was typically reached after a few millimeters (2-6) of displacement for each experiment (Fig. 3a). Until that stage, the rough surfaces exhibited slip-hardening behavior (Ohnaka, 2003) attributed to elastic deformation and yield of asperities before peak shear stress is attained. As can be readily observed from inspection of figure $3 \mathrm{~b}$, this stage was coupled with complex dilatational behavior, typically beginning with interface closure followed by interface opening, before peak shear stress is reached.

Maximum values of shear resistance did not correlated with the imposed normal stress in our experiments. The maximum shear resistance in the present study $\left(\tau / \sigma_{n}=1.25\right)$ was obtained in an experiment performed by Davidesko et al. (2014), which was performed under the lowest level of normal stress in this suite of tests, $\sigma_{n}=2 \mathrm{MPa}$. The minimum shear resistance $\left(\tau / \sigma_{n}=0.661\right)$ was measured in experiment LN6 performed under normal stress of $\sigma_{n}=10 \mathrm{MPa}$. This experiment is different from the rest because a precursory slip event occurred before peak stress was attained. The same phenomenon also occurred in experiment $L N 7\left(\sigma_{n}=15 \mathrm{MPa}\right)$ where a significant stressdrop ( 0.54 MPa) was registered before peak strength was attained. These precursory stress-drop events smoothed the stress-displacement curve, most likely dissipating some of the stored elastic 
energy prior to peak stress and consequent plastic yield of the tested interfaces. Due to the initially rough geometry of the surfaces, these precursory, uncontrolled events came as no surprise.

Figure 3. (a) Shear stress - shear displacement curves for all experiments. (b) Experiment LN11, sheared under a normal stress of $12.5 \mathrm{MPa}$. Shear stress denoted by the black curve. The colored curves depict the dilation-displacement curves of all four vertical LVDTs (labeled Xa-Xd) and the average dilation (red curve). Note that here dilation is positive and contraction is negative. Schematic illustration of LVDT layout (horizontal, labeled $\mathrm{Ya}-\mathrm{Yb}$, and vertical, labeled Xa-Xd) presented in inset, shear direction marked by arrow.

\section{Geometrical Evolution}

Roughness topography of sheared surfaces typically evolves through wear production (Power et al., 1988; Wang \& Scholz, 1994; Brodsky et al., 2011). Here we first present direct observations of geometrical variations followed by the statistical analysis of surface roughness. To prevent edge effects due to irregular fracturing at the edges of the studied surfaces roughness analysis was performed on selected zones in the center of the samples, few to dozens of centimeters long and few centimeters wide. The geometrical analyses, therefore, represent these zones on the samples only. The product for any given sample is a topographical map (expressed as a matrix) of any particular domain before and after shear. Figure 4 displays topographical maps of surfaces before and after slip, obtained from two different experiments. Both surfaces evolved through shear, but under normal stress of $\sigma_{n}=5 \mathrm{MPa}$ (Fig. $4 \mathrm{a}-\mathrm{b}$ ) the surface smoothed whereas under normal stress of 12.5 $\mathrm{MPa}$ (Fig. 4c) the surface roughened. Similar roughening is also clearly observed in other 

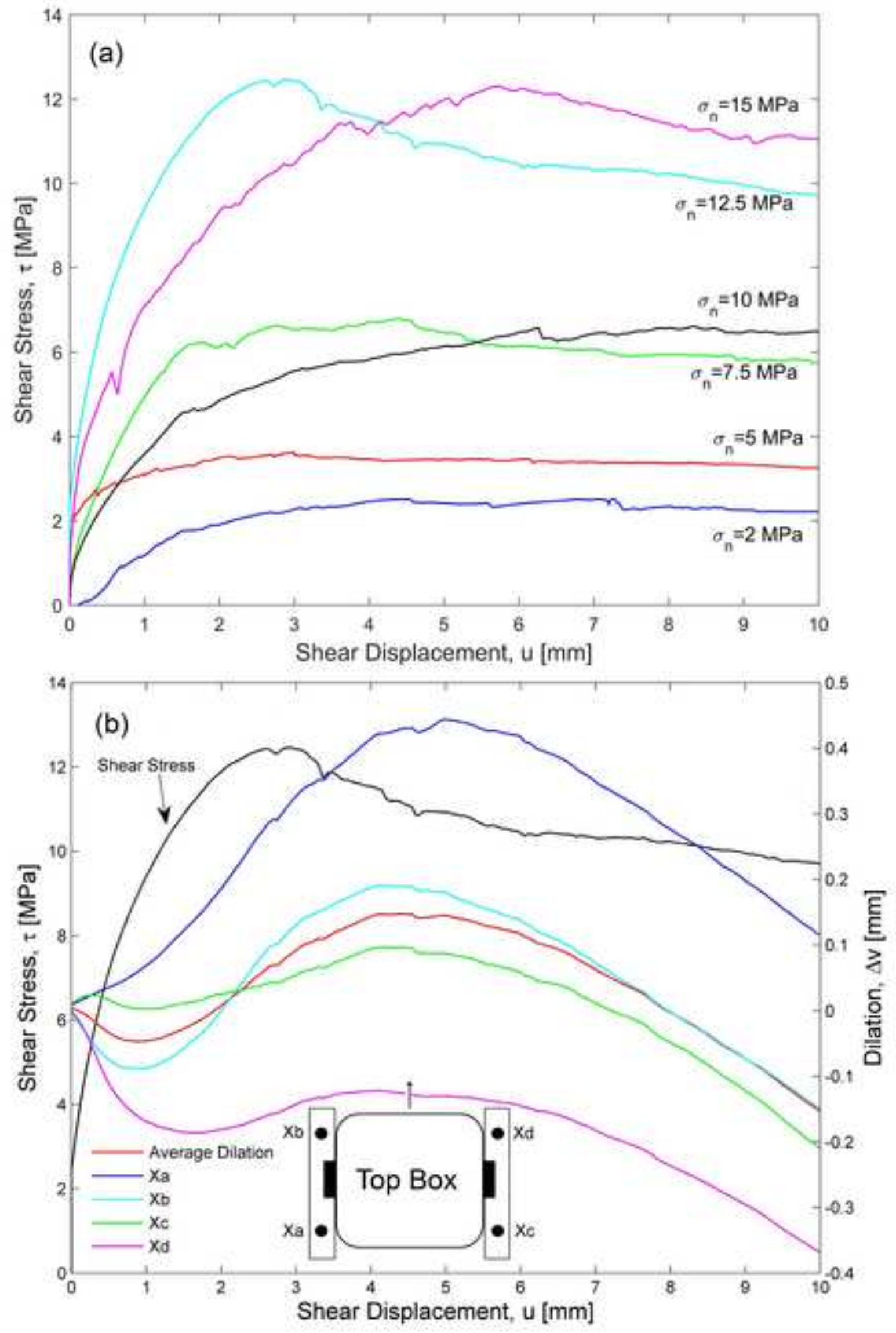
surface maps of samples sheared under 7.5 and $15 \mathrm{MPa}$ (See supplementary material). The topographical variations are demonstrated along two profiles parallel to the slip direction (Fig. $4 b, d)$. It appears that the profiles in Figure $4 b$ suggest that under normal stress of $5 \mathrm{MPa}$ the surfaces smoothed, most likely through asperity decapitation (Wang \& Scholz, 1994), which decreased the overall roughness of the surface (see also Davidesko et al., 2014).

In contrast to the smoothing mechanism observed up to normal stress of $5 \mathrm{MPa}$, the clearly observed surface roughening under higher normal stresses is novel and not trivial to explain. We believe that because the surfaces are initially rough and perfectly mating (Fig. 2) under higher normal stresses shear must be associated with significant penetrative damage. This process is best understood when the sheared surface morphology is carefully examined. Figure 5 presents the surface of the sample that was sheared under normal stress of $12.5 \mathrm{MPa}$. Three main features can be identified across the surface. First, there are undamaged zones where the original texture is exposed. Other parts of the surface are covered by smooth grooves oriented in the slip direction, similar to slip striations observed on natural faults. The third distinctive features are fractures that penetrate the edges of the shear interface to a depth of a few millimeters. These fractures (Fig. 5b) resemble Riedel shears and tensile fractures which typically develop along natural faults (Tchalenko, 1968; De Paola et al., 2008). Consider that in a given sample the fracture intensity varies across the surface, with increasing density and penetration depth near geometrical irregularities. We find that such penetrative damage is much more significant in surfaces sheared under relatively higher normal stresses. Nonetheless, islands of striated polished zones (Fig. 5 a,c) suggest simultaneous localization processes.

Figure 4. Geometrical evolution of surfaces sheared under a normal stress of $5 \mathrm{MPa}(\mathrm{a}-\mathrm{b})$ and 12.5 MPa (c-d). (a,c) pre-shear (top) and post-shear (bottom) matrices for a surfaces sheared under 
$\sigma_{\mathrm{n}}=5 \mathrm{MPa}$ and $\sigma_{\mathrm{n}}=12.5 \mathrm{MPa}$, respectively. $(\mathrm{b}, \mathrm{d})$ selected profiles in direction parallel to shear (shear direction is to the left) for a surface sheared under $\sigma_{n}=5 \mathrm{MPa}$ and $\sigma_{n}=12.5 \mathrm{MPa}$, respectively. The pre and post shear surfaces are depicted by blue and red curves, respectively. The matrices cover an area of $25 \times 14.56 \mathrm{~mm}^{2}$ and $69.9 \times 14.56 \mathrm{~mm}^{2}$ for the surface sheared under $5 \mathrm{MPa}(\mathrm{a})$ and the surface sheared under $12.5 \mathrm{MPa}(\mathrm{c})$, respectively.

Figure 5. Picture of a surface sheared under 12.5 MPa (a). Three different zones are identified; undamaged zones exhibiting the original texture of the rock, penetrative damage, exhibiting multiple fracture traces (b), and scattered zones of fine white gouge with slip-striations. Some of these contain highly polished patches (c).

Statistical description of roughness evolution is performed using power spectral density (PSD) analysis, which provides quantitative roughness values and variations as a function of length scale. The analyses are performed on both pre - and post - shear matrices that contain the selected damage zones, on profiles parallel to the slip direction. The analysis follows a procedure introduced previously (Sagy \& Brodsky, 2009; Brodsky et al., 2011; Candela et al., 2012; Davidesko et al., 2014); namely, any profile is de-trended and the discrete Fourier transform is calculated. The power is the square of the amplitudes of the coefficients and the PSD is the power spectrum normalized by the profile length. The PSD value, presented here for any given wavelength (Fig. 6), is averaged from the values calculated from several hundred profiles.

Figure 6 presents power spectral densities as function of the length scale of experimental surfaces before (blue curves) and after (red curves) $10 \mathrm{~mm}$ of shear displacement under various normal stress levels. Interestingly, the initial roughness in part of the samples does not fit well one power- 
Click here to download high resolution image
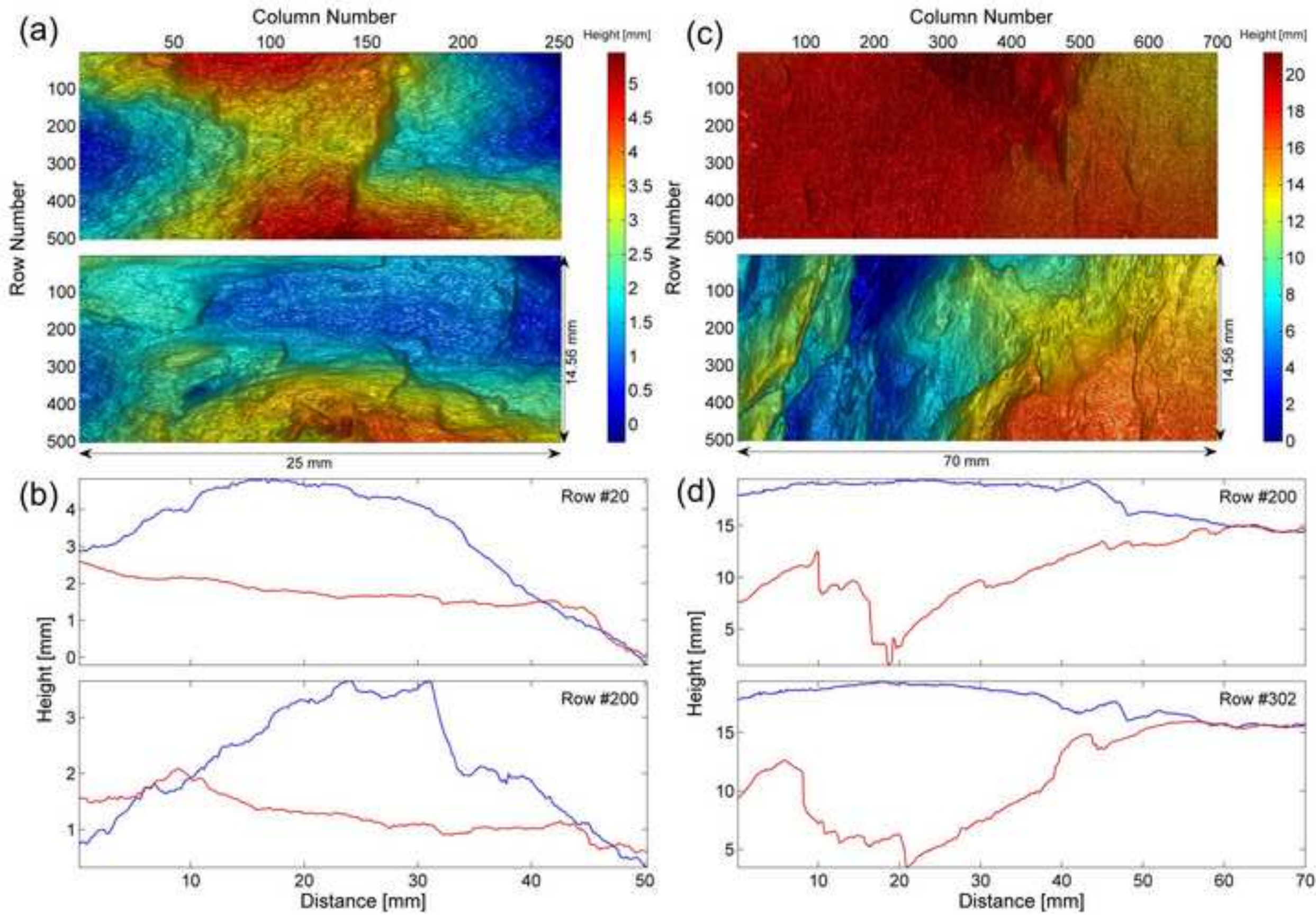
Click here to download high resolution image
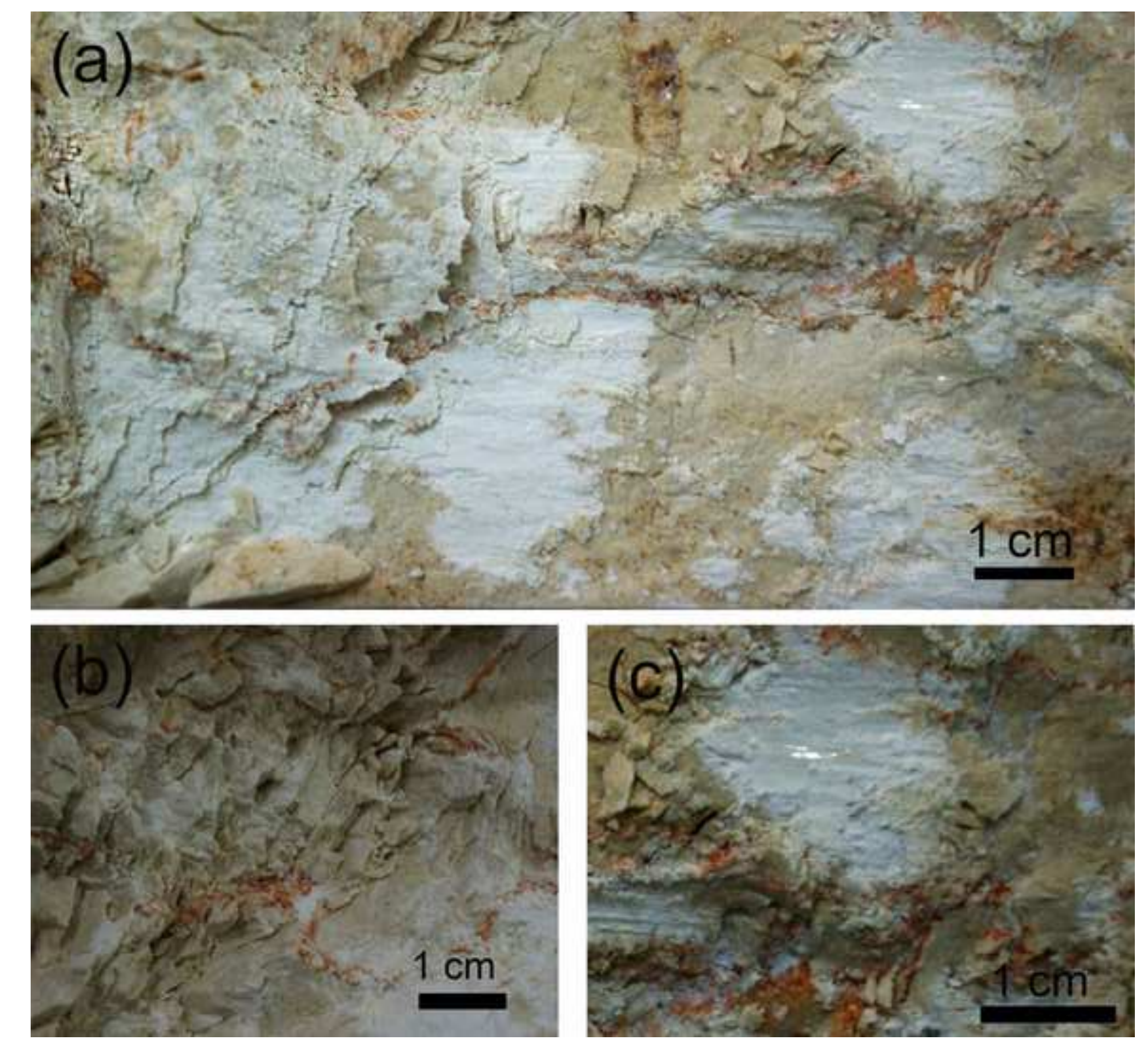
259 law and at relatively short wavelengths becomes moderate when compared to longer wavelengths

260 (Fig. 6). However, the post-shear PSD curves closely fit a power of $\beta=2.6$, or $\mathrm{H}=0.8$ (black lines).

261 Figure 6 also shows that when the surfaces are sheared under normal stresses greater than $5 \mathrm{MPa}$

262 the PSD increases at all measurable scales. The increase in PSD values corresponds to a mean

263 increase in roughness for all the profiles that make up the surface at the specified wavelength. This

264 behavior is clearly depicted in figure 7 where the PSD post to pre shear ratios are plotted as a

265 function of the tested wavelength (final $\operatorname{PSD}(\lambda)$ /initial $\operatorname{PSD}(\lambda)$ ). There is a distinct separation

266 between samples sheared under normal stress levels greater than $5 \mathrm{MPa}$, all of which exhibit

267 roughness ratios greater than 1 (roughening), and samples sheared under equal or lower normal

268 stress levels than $5 \mathrm{MPa}$, all of which exhibit roughness ratios smaller than 1 (smoothing). The

269 above observations (Figs. 4-7) suggest that penetrative brittle fracturing is enhanced with

270 increasing normal stress. During shear sliding, fragmentation occurs in and near the fractured zone

271 and consequently rock fragments are detached from the host rock. Measurements of the surface

272 irregularities indicate that roughness evolution reflects this wear mechanism.

273

Figure 6. Power spectral density roughness before (blue curves) and after (red curves) $10 \mathrm{~mm}$

shear under varying normal stresses. The slope in this bilogarithmic plot is of $\beta=2.6$,

corresponding to a Hurst exponent: $H=(\beta-1) / 2=0.8$.

277

278

Figure 7. Roughness evolution (PSD Ratio) as a function of wavelength for surfaces sheared under 279 constant normal stress. 


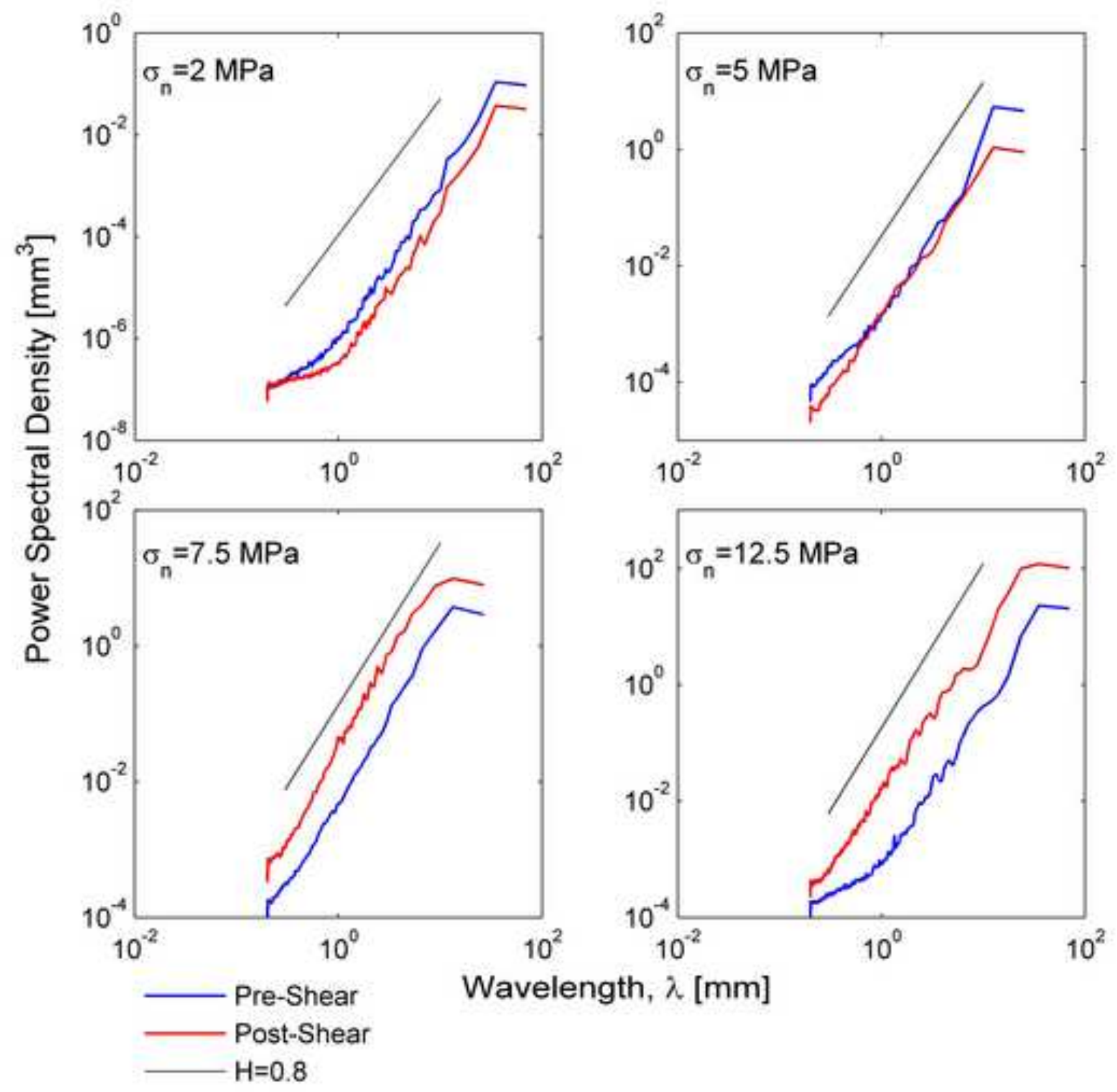


Click here to download high resolution image

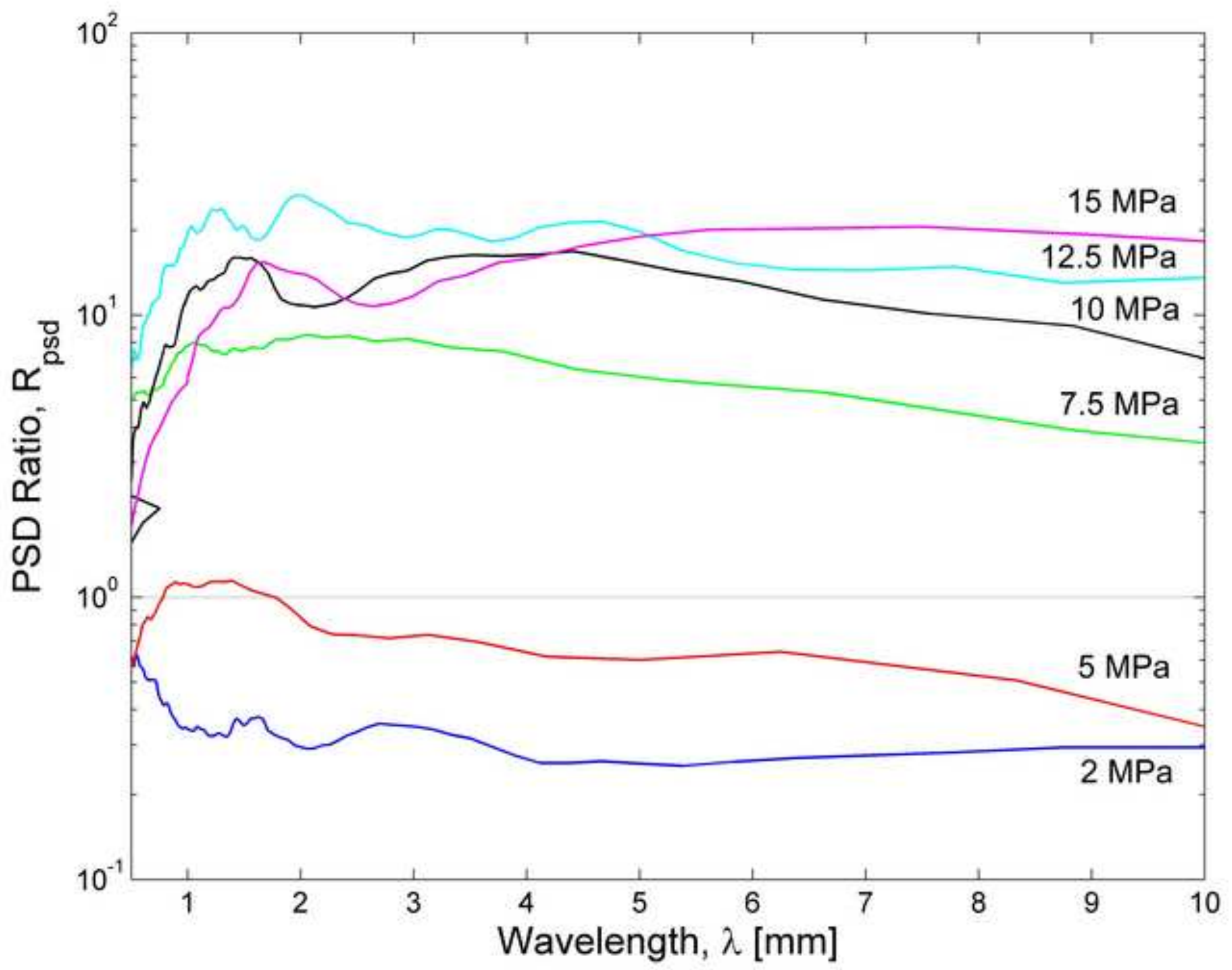




\subsection{Geometrical-Mechanical Interactions}

282 While this study focuses on roughness evolution, wear loss due to shear is a natural by-product of 283 the geometrical evolution and is therefore examined as well. Wear loss is measured by subtracting 284 the post-shear matrices from the pre-shear matrices, thus delineating the zones that experienced 285 significant damage in the resulting height-difference matrix, referred to here as the "damage matrix" (Fig. 8). Such height subtraction was possible because some parts of the post-shear surface remained intact and could therefore be used as a reference for "zeroing" the two matrices. Quantitative wear analysis is done by calculating the height difference between each compatible point in the pre- and post-shear matrices. Each point in the damage matrices represents a unit cell area of $0.1 \times 0.0291 \mathrm{~mm}^{2}$, corresponding to the resolution of the scan in both transverse and longitudinal directions, so that for each cell area we could calculate the wear volume at good approximation. A threshold height difference is set to $0.5 \mathrm{~mm}$ in order to minimize height difference incompatibility of the pre- and post-shear matrices. The wear volume is normalized by the area of the whole damage matrix (or damage zone) as follows:

$$
h_{w e a r}=\frac{\sum V_{i j}}{n A}
$$

Where $\sum V_{i j}$ is the total wear volume obtained from all the unit cells in the matrix (above threshold value), $n$ is the total number of cells in the entire matrix that entail a height difference value greater than the set threshold, and $A$ is the unit cell area. The calculated wear volume is normalized by the area of the sampled zone. Combining measurements from both mated surfaces in a given experiment provides the average wear, expressed here in terms of total wear loss volume per 
stress, but because the initial roughness of our samples although similar, was not identical, we plot the wear loss against the total mechanical shear work spent during the shearing process (Fig. 9), thus integrating the effects of normal stress, surface geometry, and material properties. The shear work due to shear sliding is obtained directly from the shear stress - shear displacement curves (e.g. 306 Fig. 3):

$$
W_{t}=\int_{0}^{10} \tau d u
$$

where $W_{t}$ is the spent shear work during sliding to a pre-specified target distance of $10 \mathrm{~mm}, \tau$ is the shear stress and $d u$ is the displacement interval. amounts of mechanical energy to be provided by the loading system. matrices.

Figure 3. Damage matrices for surfaces that were sheared under $5 \mathrm{MPa}$ (top) and $12.5 \mathrm{MPa}$ (bottom). The matrices depict zones that underwent significant damage (red areas) and undamaged zones (blue areas) that were used as reference for "zeroing" the pre and post shear

Figure 9. Wear loss and roughness ratio presented against the total shear work. The average width of the wear volume in any given sample is presented in Fig. 9a. Red dots represent values 
Click here to download high resolution image

Column Number

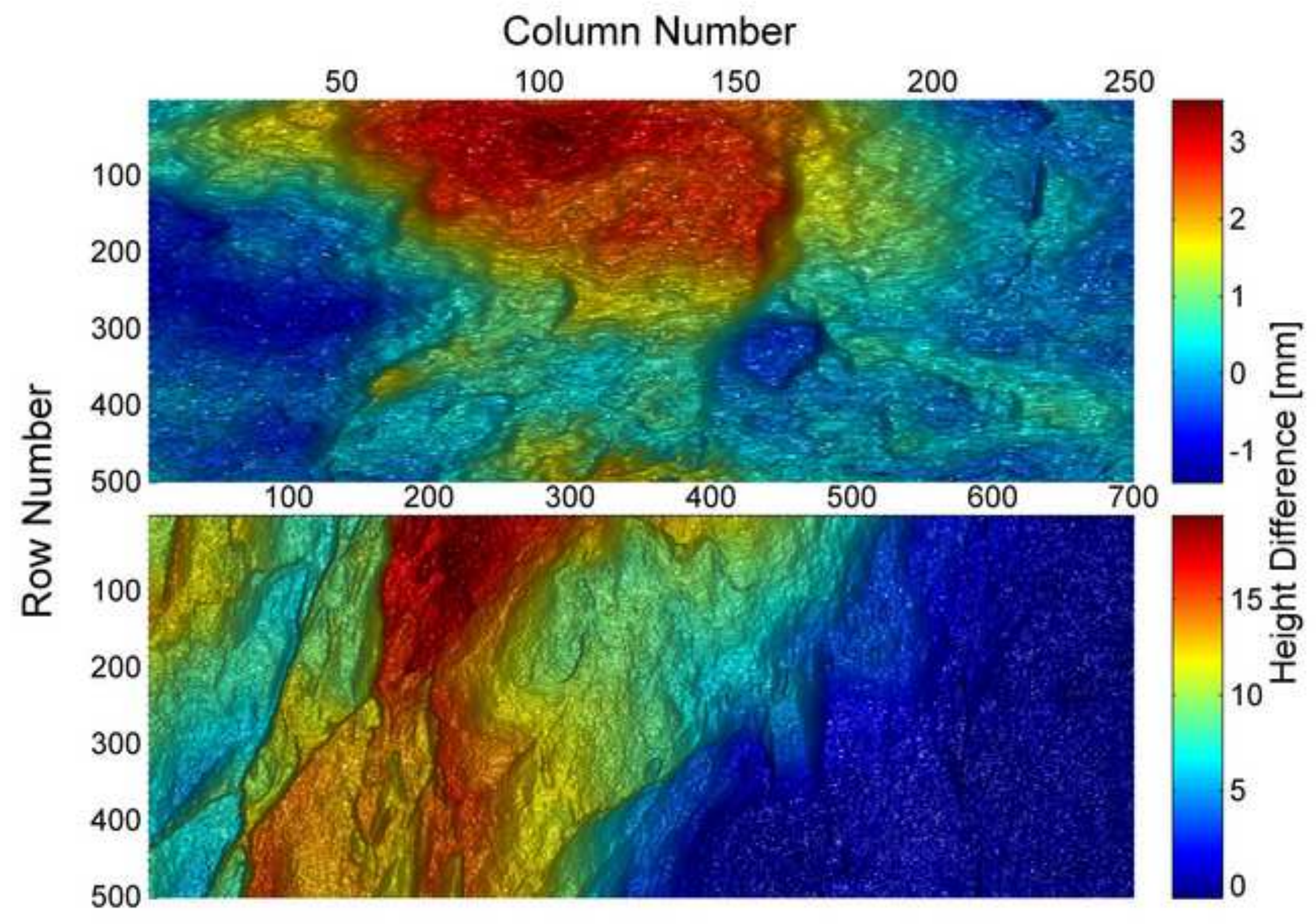



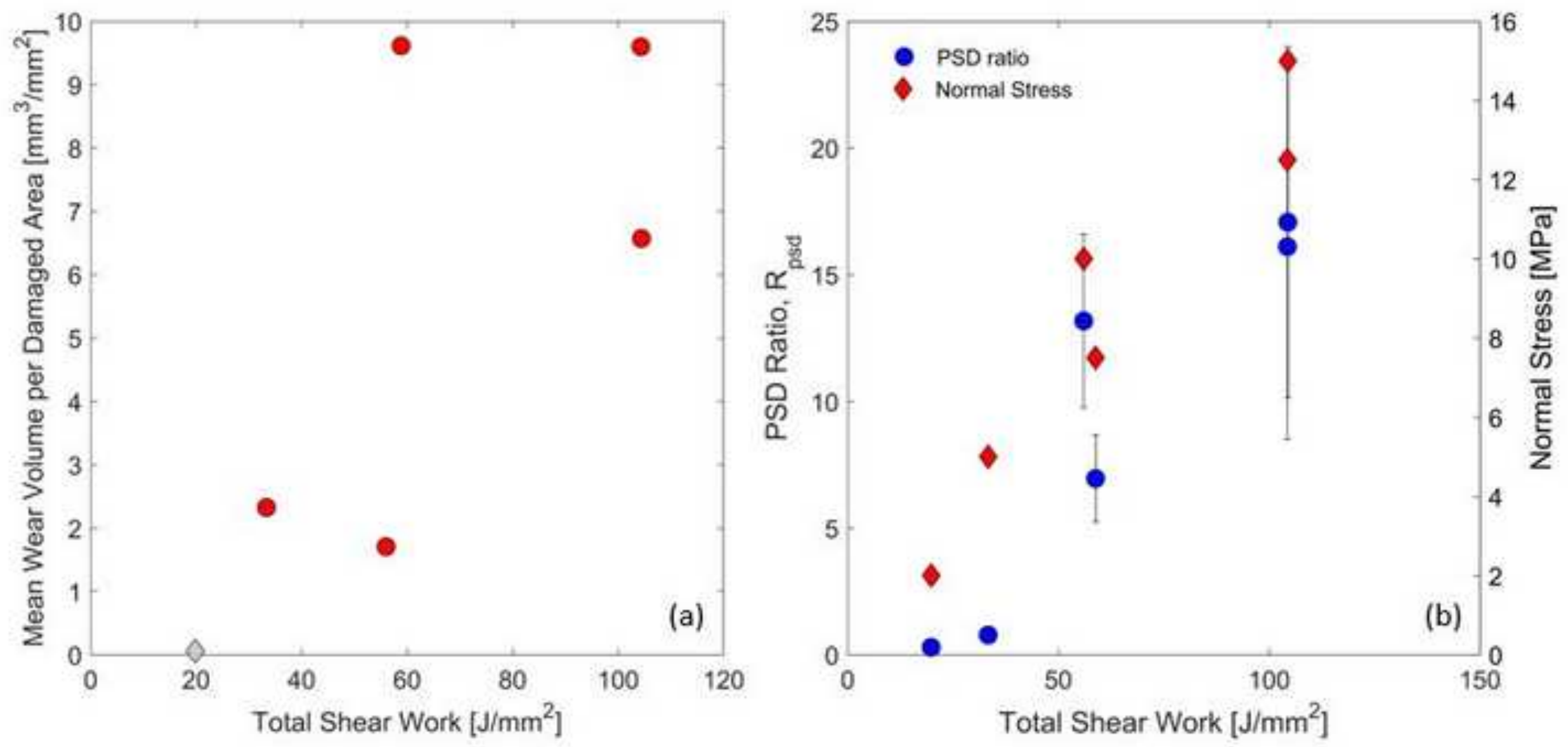
value obtained from a single surface and multiplied by two. PSD ratio and normal stress values

are presented in Fig. 9b. The error bars (right) depict one standard deviation.

\subsection{Roughness evolution}

The PSD analyses performed on the experimental slip surfaces portray the geometrical modification of the surfaces through shear. The overall picture suggests that surface roughness increases through shear under relatively high normal stresses $(\geq 7.5 \mathrm{MPa})$ and decreases under relatively low stresses ( $\leq 5 \mathrm{MPa}$ ). Previous experimental observations demonstrated that surface roughness smooths as function of slip distance (Davidesko et al., 2014). In those experiments, surface roughness of tensile fracture were fitted well by a similar power-law, before and after shear, suggesting that when constant normal stress is applied during shear displacement the power spectral density of the surface can be described by:

$$
p(\lambda)=k_{(d)} \lambda^{\beta}
$$

Where $\beta$ is the slope of the PSD lines (in logarithmic space) and $k_{(d)}$ is the slip dependent coefficient of the smoothing process. It is demonstrated here that when the displacement is fixed and the normal stress is variable, the PSD can be described by:

$$
p(\lambda)=k_{(N)} \lambda^{\beta}
$$

where $k_{(N)}$ is the normal stress dependent coefficient of the roughening process. The prefactor $k$ is therefore the parameter that chiefly varies during our shear experiments. Interestingly, computer simulations demonstrated that the prefactor of the self-affine surface roughness is the main component of roughness that affects energy dissipation during faulting (Newman \& Griffith, 2014).

On the other hand, In most sheared surfaces of both sets of experiments, the power $\beta$ exhibits a typical value of 2.6, in direction of slip along the measured scales, which in self-affine surfaces corresponds to a roughness (or Hurst) exponent of $\mathrm{H}=0.8$, as measured in previous studies 
344 (Bouchaud, 1997), where $\beta=1+2 \mathrm{H}$ (Barabasi \& Stanley, 1995). It is therefore suggested that this 345 roughness exponent might represent a more general multiscale self-affine roughness as suggested 346 previously both for tensile and shear fractures (e.g. Bouchaud et al., 1990; Amitrano and 347 Schmittbuhl, 2002; Renard et al., 2006).

348 Examination of the experimental surfaces more locally reveals that the tested surfaces undergo 349 smoothing and roughening at different localities (Figure 10a). The pre- and post-shear curves 350 display an overall increase in surface roughness; however, when different zones in the same post351 shear surface matrix are examined areas of different roughness are evident. The rough zone 352 (magenta colored curve) exhibits the maximum PSD values for each wavelength. In contrast, the smooth zone showing striations with no intensive penetrative damage, exhibits PSD values that are much closer to the initial values before slip has occurred. When two PSD functions with equal power $(\beta=2.6)$ but different prefactor values are plotted along with the surface data, it can be concluded that while some variations in the power exist in the data, the predominant change in roughness is manifested mathematically as an increase or decrease in the prefactor $(k)$ value. Following our observation that the prefactor is normal-stress-dependent, and its value increases with normal stress (Figs. 6-7), we conclude that the same process also occurs locally. The striation zones have presumably experienced a lower local normal stress than the rough ones. These local variations of the normal stress are mostly influenced by the initial geometry of the fault, as evident by direct observations (Fig. 5) and suggested by models of stress distribution near rough fault surfaces (Chester \& Chester, 2000; Sagy \& Brodsky, 2009; Griffith et al., 2010). We thus conclude that initial roughness strongly influences post slip damage intensity and surface geometry.

Figures 6 and 10a also demonstrate that at short length scales $(<1 \mathrm{~mm})$ some of the initial tensile fracture surfaces display a kink in the PSD values. Examination of thin sections reveals that the average grain size of the tested rock before shear is $0.4 \mathrm{~mm}$, and therefore the bend in the PSD 
values is best interpreted as associated with the typical grain scale of the samples ( 1- $0.1 \mathrm{~mm}$ ).

Such small-scale cutoff is commonly observed in tensile fractures for numerous materials (Bouchaud, 1997). Interestingly, this cutoff remains in post-shear PSD curves for the surface sheared under $2 \mathrm{MPa}$ (Fig. 6), but diminishes in surfaces sheared under higher normal stresses (Figs. $6,10 a)$. Figure $10 \mathrm{~b}$ presents the most extreme case of deviation of initial roughness from a powerlaw. The plot includes measurements from the high resolution lens of $50 \mathrm{~mm}$, which enlarges the scanning resolution down to less than $0.05 \mathrm{~mm}$. The kink in the pre-shearing roughness is reduced in the post-shear roughness and "moves" around smaller wavelength. This is attributed to higher efficiency of fragmentation in the grain scale during shear, as the grains themselves are fractured. discussed by Amitrano \& Schmittbuhl (2002).

Figure 10. (a) PSD curves for different zones of unequal roughness for a surface sheared under 12.5 $\mathrm{MPa}$. The pre and post shear curves refer to the whole surface before and after shear, respectively. The rough and striation zone curves refer to two distinct zones in the post-shear surface that underwent roughening and smoothing, respectively. The two black solid lines are upper and lower bounds to the data featuring different values of $k$. (b) Power spectrum curves for a surface sheared under $15 \mathrm{MPa}$. Note the cross-over between the pre shear (blue) and post shear (red) curves around a wavelength of $0.4 \mathrm{~mm}$.

\subsection{Applications for natural faulting}

The initial setup presented here is of a tensile fracture that is reactivated by shear. Such a slip mode is common in natural environments (Segall \& Pollard, 1983; Martel et al., 1988; Di Toro \& Pennacchioni, 2004). Moreover, field and experimental observations as well as theoretical analyses 
Click here to download high resolution image
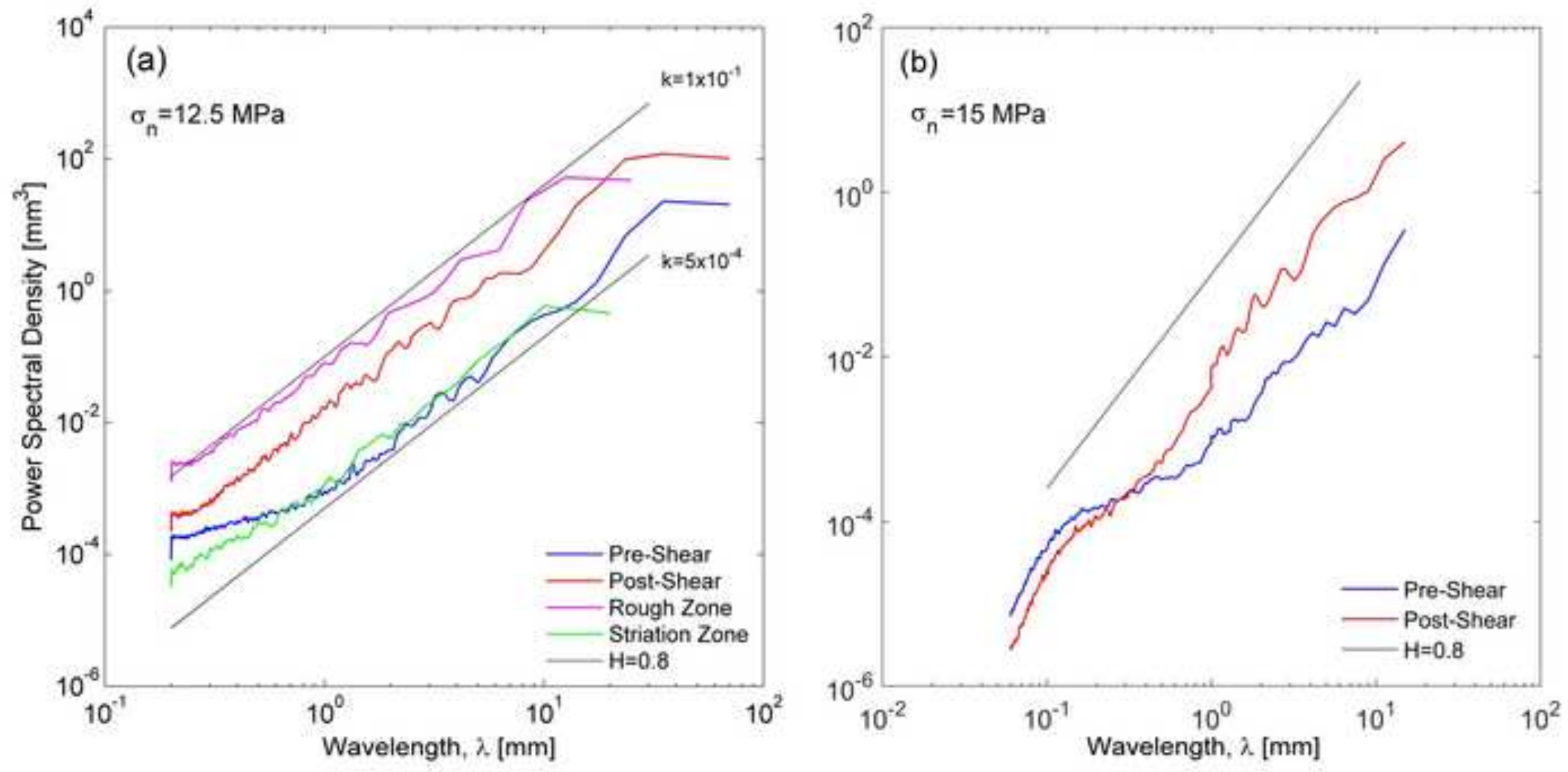
demonstrate that the initial inelastic deformation of brittle rocks, even under compression, usually includes tensile mode fracturing, while shear occurs only when these fractures interact (Segall \& Pollard, 1983; Ashby \& Sammis, 1990; Reches \& Lockner, 1994). More broadly, one can interpret the presented configuration as a simplification of the shear of a multiscale interlocked rough fault, as is the case for faults along the entire range of length scales. At large scales, even mature faults can express significant roughness (Wang \& Bilek, 2011).

Friction experiments under constant loading conditions display in some configurations strain hardening and strain weakening stages, followed by low resistance to shear (e.g. Ohnaka, 2003). stress, roughness, wear rate and resistance to shear remain statistically stable, (Archard, 1953; 
simulate fault patches which absorbed slip amounts larger than their length. We also note that slip velocity and normal stress further affect surface roughness at this stage (Boneh et al., 2013; Chen et al., 2013; Fondriest et al., 2013; Siman-Tov et al., 2015).

Finally, natural fault roughness values decrease with net slip (Sagy et al., 2007; Bistacchi et al. 2011), albeit very gradually (Brodsky et al., 2011). Normal stress variations, as presented here, could be important to this evolution. Roughness and wear loss in the present testing configuration evolve throughout brittle damage and increase with the mechanical shear work (Fig. 9). Following these results and previous theoretical analysis (Newman \& Griffith., 2014) we speculate that the energy dissipation during natural slip is affected both by the level of normal stress and by the initial earthquake.

\section{Summary and conclusions}

Our experimental configuration in which the surfaces are: a) initially rough, b) include multiscale geometrical irregularities, c) initially interlocked, and d) sheared to distances that are comparable to the roughness amplitude of the surface, is well suited to simulate natural faulting. Such a testing associated with polishing and smoothing of surface asperities, we find that deformation associated with shearing extends beyond the immediate zone of the asperities and that this deformation becomes more intensive with increasing normal stress. We demonstrate here that roughness evolution is a complex mechanism that consists of simultaneous roughening and smoothing in a 
439 given surface. Roughening occurs as part of damage development during strain hardening stage 440 while gradual localization and smoothing occur during strain weakening. Under constant stress, the 441 final roughness value depends on the slip amount (Davidesko et al., 2014). When the slip distance 442 and the loading velocity are constant, the surface becomes rougher with increasing normal stress. 443 Consequently, the roughness of the surface after shear can be higher than the initial roughness, an 444 experimental finding never reported before.

445 We show that roughness, as function of measured wavelength, fits a power-law with power value 446 of $\beta \sim 2.6$, or Hurst exponent of $\mathrm{H}^{\sim 0.8}$, assuming characteristic self-affine topography parallel to the 447 slip direction (Figs. 6 and 10). Interestingly, this power is stable in the sheared surfaces even when 448 the initial roughness does not fit a power-law, indicating that this characteristic roughness is an 449 attractor for the morphology developed under brittle shear. Therefore, continuous shear can 450 enlarge the range of length scales which statistically obey power-law roughness. The final roughness of the surface, which depends on the initial geometry, the level of normal stress, and the 452 imposed sliding distance, is expressed by the evolution of the scaling-law prefactor. This value 453 increases with normal stress but decreases with continuous slip.

Acknowledgements

456 We thank Telemaco Tesei and W. Ashley Griffith for their insightful comments and constructive 457 review which helped improve this manuscript. This study is funded by Israel Science Foundation 458 grant No. 929/10 and by USIAS Fellowship, University of Strasbourg.

\section{References}

Amitrano, D., \& Schmittbuhl, J. (2002). Fracture roughness and gouge distribution of a granite shear band. 
Archard, J. F. (1953). Contact and rubbing of flat surfaces. Journal of Applied Physics, 24, 8, 981-988.

Ashby, M. F., and C. G. Sammis (1990), The damage mechanics of brittle solids in compression, Pure and applied geophysics, 133, $489-521$.

Barabási, A.-L., \& Stanley, H.E. (1995). Fractal concepts in surface growth. Cambridge University Press.

Barton, N. (1976). Rock Mechanics Review: The Shear Strength of Rock and Rock Joints. International Journal of Rock Mechanics, Mining Science and Geomechanics Abstracts, 13, 255-279.

Ben-Zion, Y., \& Sammis, C. G. (2003). Characterization of fault zones. Pure and Applied Geophysics, 160(3-4), 677-715.

Bistacchi, A., Griffith, W. A., Smith, S. A., Di Toro, G., Jones, R., \& Nielsen, S. (2011). Fault roughness at seismogenic depths from LIDAR and photogrammetric analysis. Pure and applied geophysics, 168(12), 2345-2363.

Boneh, Y., Sagy, A., \& Reches, Z. (2013). Frictional strength and wear-rate of carbonate faults during highvelocity, steady-state sliding. Earth and Planetary Science Letters, 381, 127-137.

Boneh, Y., Chang, J., Lockner, D. A., and Reches, Z. (2014). Fault Evolution by Transient Processes of Wear and Friction. Pure and Applied Geophysics, Vol. 171, Issue 11, 3125-3141.

Bouchaud, E., Lapasset, G., \& Planès, J. (1990). Fractal dimension of fractured surfaces: a universal value? Europhysics Letters, 13(1), 73.

Bouchaud, E. (1997). Scaling properties of cracks. Journal of Physics: Condensed Matter, 9(21), 4319.

Bowden, F. P. and Tabor, D. (1950). The Friction and Lubrication of Solids. Oxford: Oxford University Press.

Brodsky, E. E., Gilchrist, J. J., Sagy, A., \& Collettini, C. (2011). Faults smooth gradually as a function of slip. Earth and Planetary Science Letters, 302, 185-193.

Byerlee, J. (1978). Friction of Rocks. Pure and Applied Geophysics, 116, 615-626.

Candela, T., Renard, F., Klinger, Y., Mair, K., Schmittbuhl, J., \& Brodsky, E. E. (2012). Roughness of fault surface over nine decade of length scales. Journal of Geophysical Research 117(B8).

Chen, X., Madden, A. S., Bickmore, B. R., \& Reches, Z. E. (2013). Dynamic weakening by nanoscale smoothing during high-velocity fault slip. Geology, 41(7), 739-742. 
Chester, F. M., \& Logan, J. M. (1986). Implications for mechanical properties of brittle faults from observations of the Punchbowl fault zone, California. Pure and Applied Geophysics, 124, 79-106.

Chester, F. M., \& Chester, J. S. (2000). Stress and deformation along wavy frictional faults. Journal of Geophysical Research, 105(B10), 23421-23430.

Davidesko, G. (2013). Evolution of Surface Roughness Through Shear, M.Sc. Thesis. Beer-Sheva, Israel: BenGurion University of the Negev.

Davidesko, G., Sagy, A., \& Hatzor, Y. H. (2014). Evolution of slip surface roughness through shear. Geophysical Research Letters, 41(5), 1492-1498.

De Paola, N., Collettini, C., Faulkner, D. R., \& Trippetta, F. (2008). Fault zone architecture and deformation processes within evaporitic rocks in the upper crust. Tectonics, 27(4).

Dieterich, J. H., \& Kilgore, B. D. (1994). Direct observation of frictional contacts: New insights for statedependent properties. Pure and Applied Geophysics, 143(1-3), 283-302.

Di Toro, G., \& Pennacchioni, G. (2005). Fault plane processes and mesoscopic structure of a strong-type seismogenic fault in tonalites (Adamello batholith, Southern Alps). Tectonophysics, 402(1), 55-80.

Faulkner, D. R., Jackson, C. A. L., Lunn, R. J., Schlische, R. W., Shipton, Z. K., Wibberley, C. A. J., \& Withjack, M. O. (2010). A review of recent developments concerning the structure, mechanics and fluid flow properties of fault zones. Journal of Structural Geology, 32(11), 1557-1575.

Fondriest, M., Smith, S. A., Candela, T., Nielsen, S. B., Mair, K., \& Di Toro, G. (2013). Mirror-like faults and power dissipation during earthquakes. Geology, 41(11), 1175-1178.

Griffith, W. A., S. Nielsen, G. Di Toro, and S. A. Smith (2010), Rough faults, distributed weakening, and offfault deformation, Journal of Geophysical Research, 115, B08409, doi:10.1029/2009JB006925.

Grasselli, G., J. Wirth, and P. Egger (2002). Quantitative three-dimensional description of a rough surface and parameter evolution with shearing. International Journal of Rock Mechanics and Mining Sciences 39.6: 789-800.

Lyakhovsky, V., Sagy, A., Boneh, Y., \& Reches, Z. (2014). Fault wear by damage evolution during steady-state slip. Pure and Applied Geophysics,171(11), 3143-3157. 
Mandelbrot, B. B. (1983). The Fractal Geometry of Nature, W. H. Freeman and Company, New York, 495 p.

Martel, S. J., Pollard, D. D., \& Segall, P. (1988). Development of simple strike-slip fault zones, Mount Abbot quadrangle, Sierra Nevada, California. Geological Society of America Bulletin, 100(9), 1451-1465.

Newman, P. J., \& Griffith, W. A. (2014). The work budget of rough faults.Tectonophysics, 636, 100-110.

Ohnaka, M. (2003). A constitutive scaling law and a unified comprehension for frictional slip failure, shear 
540 Siman-Tov, S., Aharonov, E., Sagy, A., \& Emmanuel, S. (2013). Nanograins form carbonate fault mirrors. Geology, 41(6), 703-706.

542 Siman-Tov, S., Aharonov, E., Boneh, Y., \& Reches, Z. (2015). Fault mirrors along carbonate faults: Formation 543 and destruction during shear experiments. Earth and Planetary Science Letters, 430, 367-376.

544 Tchalenko, J. (1968). The evolution of kink-bands and the development of compression textures in sheared $545 \quad$ clays. Tectonophysics, 6, 159-174.

546 Wang, W., \& Scholz, C. H. (1994). Wear processes during frictional sliding of rock: A theoretical and 547 experimental study. Journal of Geophysiacal Research, Vol.99, No. B4, pp. 6789-6799.

548 Wang, K., \& Bilek, S. L. (2011). Do subducting seamounts generate or stop large earthquakes?. Geology, 39(9), 819-822.

550 Wesnousky, S. G. (1988). Seismological and structural evolution of strike-slip faults. Nature, v. 335, 340-342.

551 Wibberley, C. A. J., Yielding, G. \& Di Toro, G. (2008). Recent advances in the understanding of fault zone 552 internal structure: a review. Geological Society, London, Special Publications 299.1, 5-33. 


\section{Geometrical evolution of interlocked rough slip surfaces: The role of}

\section{normal stress}

Nir Badt ${ }^{1}$, Yossef H. Hatzor ${ }^{1}$, Renaud Toussaint ${ }^{2}$ and Amir Sagy ${ }^{3 *}$

1. Department of Geological and Environmental Science, Ben-Gurion University of the Negev, Beer Sheva 84105, Israel

2. Institut de physique du globe de Strasbourg, 5, rue René Descartes - F-67084 Strasbourg cedex

3. Geological Survey of Israel, 30 Malkhe Israel, Jerusalem 95501, Israel

*Corresponding author: asagy@gsi.gov.il

\section{Supplementary Material}

Table 1. Results from direct shear experiments

\begin{tabular}{lcccc}
\hline Experiment & $\begin{array}{c}\text { Normal } \\
\text { Stress, } \boldsymbol{\sigma}_{\mathbf{n}}[\mathrm{MPa}]\end{array}$ & $\begin{array}{c}\text { Peak Shear } \\
\text { Resistance, } \boldsymbol{\tau} / \boldsymbol{\sigma}_{\mathbf{n}}\end{array}$ & $\begin{array}{c}\text { Peak Shear } \\
\text { Stress, } \boldsymbol{\tau}[\mathrm{MPa}]\end{array}$ & $\begin{array}{c}\text { Stress-Drop, } \Delta \boldsymbol{\tau} \\
{[\mathbf{M P a}]}\end{array}$ \\
\hline L10 & 2 & 1.25 & 2.5 & 0.224 \\
LN1 & 5 & 0.724 & 3.622 & 0.369 \\
LN10 & 7.5 & 0.905 & 6.787 & 0.989 \\
LN6 & 10 & 0.661 & 6.61 & 0.142 \\
LN11 & 12.5 & 0.997 & 12.458 & 2.673 \\
LN5 & 15 & 0.862 & 12.93 & 2.223 \\
LN7 & 15 & 0.821 & 12.312 & 1.248 \\
\hline
\end{tabular}

*Data from Davidesko et al. (2014) 


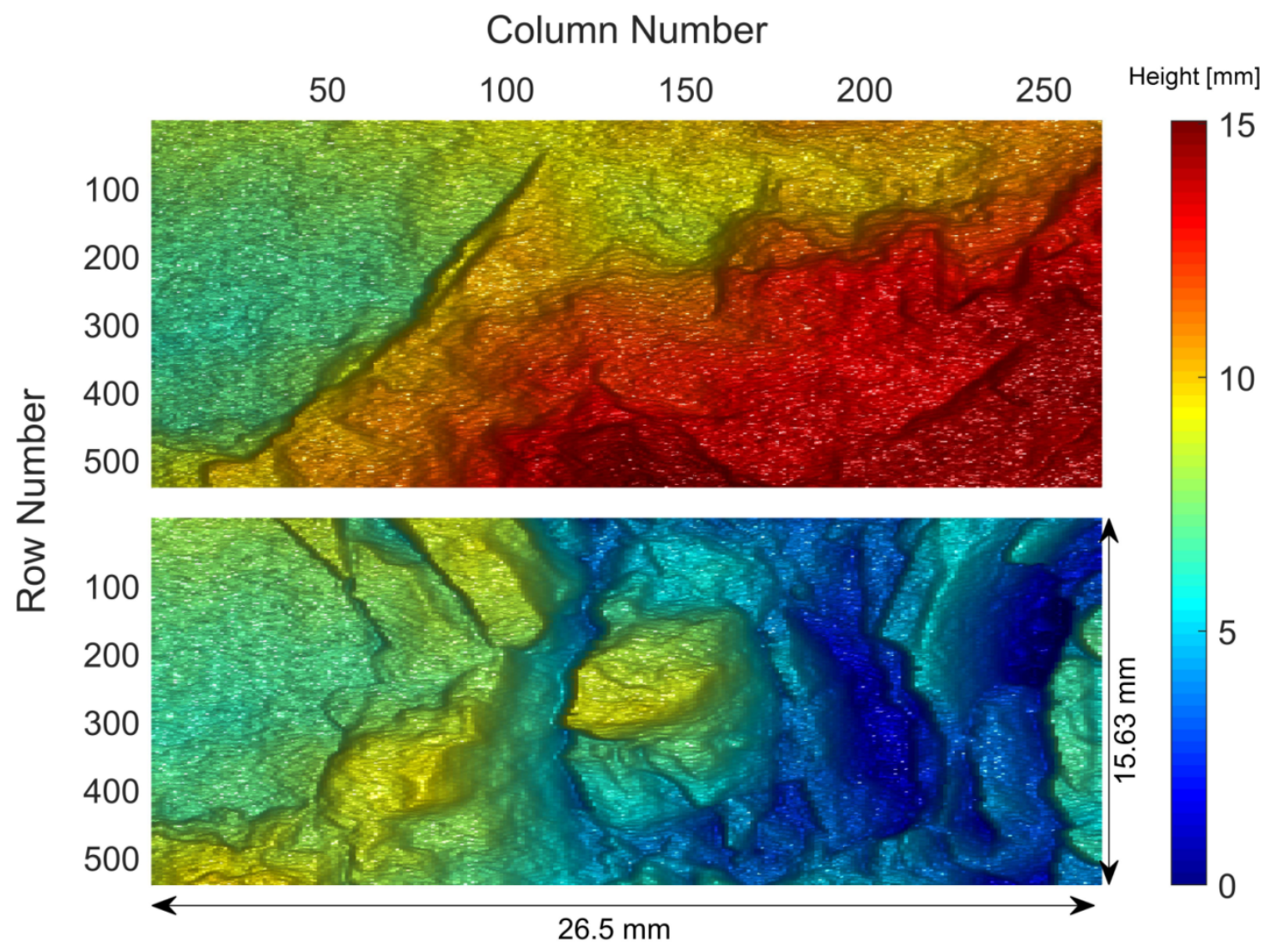

Figure 1. Surface matrices before (top) and after (bottom) shear for an experiment sheared under 7.5 $\mathrm{MPa}$. 


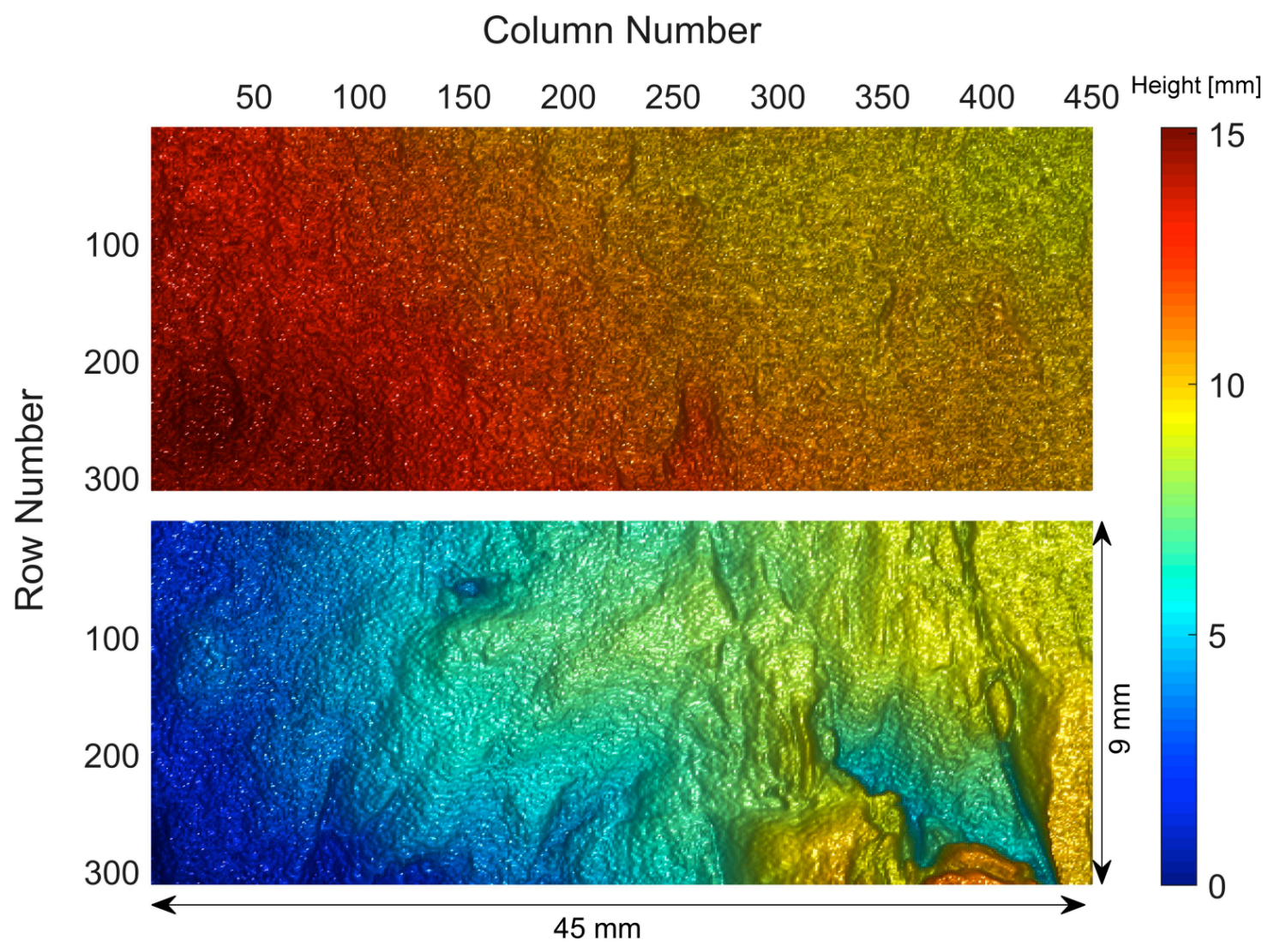

Figure 2. Surface matrices before (top) and after (bottom) shear for an experiment sheared under 15 MPa. 